\title{
Alignment of school discipline with positive behavioural interventions and supports: The case of one disadvantaged urban South African Primary School
}

\begin{tabular}{|c|c|}
\hline \multicolumn{2}{|c|}{$\begin{array}{l}\text { Authors: } \\
\text { Joseph Calvin Gagnon }{ }^{1} \\
\text { Frederick J. Sylvester } \\
\text { Kathryn Marsh }\end{array}$} \\
\hline \multicolumn{2}{|c|}{$\begin{array}{l}\text { Affiliations: } \\
{ }^{1} \text { Department of Special } \\
\text { Needs Education, Faculty of } \\
\text { Education Sciences, } \\
\text { University of Helsinki, } \\
\text { Helsinki, Finland }\end{array}$} \\
\hline $\begin{array}{l}{ }^{2} \text { Department } \\
\text { Psychology, F } \\
\text { Education, Un } \\
\text { Western Cape } \\
\text { South Africa }\end{array}$ & $\begin{array}{l}\text { Educational } \\
\text { culty of } \\
\text { iversity of the } \\
\text { Cape Town, }\end{array}$ \\
\hline \multicolumn{2}{|c|}{$\begin{array}{l}{ }^{3} \text { Unumb Center of } \\
\text { Neurodevelopment, Columbia, } \\
\text { United States of America }\end{array}$} \\
\hline \multicolumn{2}{|c|}{$\begin{array}{l}\text { Corresponding author: } \\
\text { Joseph Calvin Gagnon, } \\
\text { joseph.gagnon@helsinki.fi }\end{array}$} \\
\hline \multicolumn{2}{|c|}{$\begin{array}{l}\text { Dates: } \\
\text { Received: } 28 \text { Apr. } 2020 \\
\text { Accepted: } 29 \text { Sept. } 2021 \\
\text { Published: } 18 \text { Nov. } 2021\end{array}$} \\
\hline \multicolumn{2}{|c|}{$\begin{array}{l}\text { How to cite this article: } \\
\text { Gagnon, J.C., Sylvester, F.J. } \\
\text { \& Marsh, K., 2021, 'Alignment } \\
\text { of school discipline with } \\
\text { positive behavioural } \\
\text { interventions and supports: } \\
\text { The case of one disadvantaged } \\
\text { urban South African Primary } \\
\text { School', South African Journal } \\
\text { of Childhood Education 11(1), } \\
\text { a1022. https://doi.org/ } \\
\text { 10.4102/sajce.v11i1.1022 }\end{array}$} \\
\hline \multicolumn{2}{|c|}{$\begin{array}{l}\text { Copyright: } \\
\text { (C) 2021. The Authors. } \\
\text { Licensee: AOSIS. This work } \\
\text { is licensed under the } \\
\text { Creative Commons } \\
\text { Attribution License. }\end{array}$} \\
\hline Read online: & \\
\hline 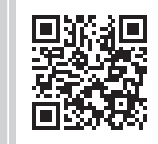 & $\begin{array}{l}\text { Scan this QR } \\
\text { code with your } \\
\text { smart phone or } \\
\text { mobile device } \\
\text { to read online. }\end{array}$ \\
\hline
\end{tabular}

Background: Positive behavioural interventions and supports (PBIS) is a framework that aligns with the South African Department of Education's Alternatives to Corporal Punishment.

Aim: The aim of this study is to provide a snapshot of the extent to which policies and practices in a disadvantaged South African primary school align with PBIS.

Setting: The study was conducted at a South African primary school with grades kindergarten to Grade 7 in an urban disadvantaged community.

Methods: Twenty-eight teachers, administrators and non-educational school staff completed a survey that addressed: (1) common behaviour problems; (2) the extent to which the school implements five core features of PBIS and (3) the existence of a crisis prevention and intervention plan.

Results: In this disadvantaged school, there is little evidence that (1) a cohesive, evidencebased schoolwide behaviour plan exists that includes multi-tiered systems of support; (2) staff have the expertise to implement a positive and proactive behaviour plan or are provided adequate professional development; (3) staff follow the plan and are held accountable for following it and (4) a representative leadership team provides oversight and direction regarding the plan by using learner behaviour data.

Conclusion: The results indicate that there is a lack of multi-tiered systems of behavioural support and a continued reliance on reactive and punitive approaches to learner behaviour. Moreover, staff do not adhere to the schoolwide behaviour plan, are not held accountable for doing so, and need training in key areas of behaviour management.

Keywords: South Africa; disadvantaged schools; positive behavioural interventions and prevention, learner behaviour.

\section{Introduction}

Despite governmental efforts, many South African (SA) schools remain unsafe for children (Souverein et al. 2016). Vandalism, stealing, fighting and disrespect of teachers are significant challenges for schools (Marais \& Meier 2010). Moreover, physical, verbal, social and sexual bullying are pervasive (Centre for Justice and Crime Prevention and the Department of Basic Education 2012), with over $80 \%$ of youth reporting problems with bullying at their schools (Ncontsa \& Shumba 2013). Ncontsa and Shumba also noted that almost $20 \%$ of youth reported having been attacked at schools. Problems with peer-to-peer violence and bullying are even more pronounced in disadvantaged schools (i.e. schools in areas with low socio-economic status) (Winaar, Arends \& Beku 2018). These disadvantaged schools typically serve coloured or black youth, and exist in areas known to be most negatively affected by former apartheid policies (South African Human Rights Commission \& UNICEF 2016).

However, most violence experienced by children at school occurs in the classroom, often at the hands of the teacher (Hanaya, McDonald \& Balie 2020). Although corporal punishment (CP) was banned in schools over two decades ago, its use remains ubiquitous (Women, Children and People with Disabilities, Republic of South Africa 2014). The use of CP with learners is harmful and can result in serious short-term (e.g. physical harm, truancy, anti-social behaviour) and longterm (e.g. risk of mental disorders) outcomes (Gershoff \& Font 2016; Mthanti \& Mncube 2014). The 
trend of using $\mathrm{CP}$ continues, despite guidance from the South African Department of Education (2000) in its publication of the Alternatives to Corporal Punishment (ATCP). Although rather broad, the ATCP does include effective, proactive approaches that can positively affect youth behaviour, including: (1) adopting a whole-school approach to youth behaviour; (2) using an interdisciplinary approach to address youth behaviour; (3) establishing, posting and consistently implementing rules; (4) implementing cognitive-behavioural interventions (e.g. conflict management and problem solving); (5) reinforcing appropriate behaviour and (6) implementing graduated interventions and consequences based on learner needs.

Nevertheless, many teachers lack classroom management skills and continue to believe in and rely on CP (Hanaya et al. 2020; Moyo, Khewu \& Bayaga 2014). There are few published empirical studies focusing on behavioural interventions in SA schools and teachers assert that they have no practical and effective alternatives to CP (Marais \& Meier 2010). It is within this context that SA researchers have begun to advocate for the implementation of positive behavioural interventions and supports (PBIS) as a potential way forward (Dwarika 2020).

\section{Theoretical framework}

The PBIS is an approach to providing a safe, predictable, consistent and supportive social climate. It is used in tens of thousands of schools in 22 countries (Horner \& Macaya 2018). In contrast to reactive and punitive approaches like $\mathrm{CP}, \mathrm{PBIS}$ is a multi-tiered continuum of evidence-based proactive practices that promote appropriate learner behaviour (Noltemeyer et al. 2019). Within this model, youth and staff are supported by three tiers: (1) facility-wide behavioural policies and practices, (2) selective intervention strategies that provide targeted support for those at high risk of difficulties and (3) individualised intensive interventions for those with more serious behavioural needs. The Technical Assistance Centre (TAC) on PBIS (2015) identified following seven core features of PBIS:

1. universal and comprehensive screening;

2. a continuum of evidence-based interventions;

3. leadership team implementation and coordination;

4. content expertise and fluency;

5. process integrity;

6. continuous progress monitoring and

7. cultural and contextual relevance.

The PBIS model is based on the notion that delivering all three tiers of progressively increasing support and 'addressing these seven core features will result in improved and sustainable appropriate and prosocial learner behaviour' (Gagnon, Barber \& Soyturk 2020:177). In fact, PBIS implementation is associated with reductions in office discipline referrals and in suspensions (Noltemeyer et al. 2019). A recent meta-analysis revealed that it resulted in significant improvements in learner behaviour and academic achievement, and improved school organisational health (Lee \& Gage 2019).

The PBIS aligns well with central components of the ATCP and is appropriate for the SA context, particularly in its rejection of both $\mathrm{CP}$ and the sole reliance on reactive and punitive approaches (Dwarika 2020). However, research on PBIS in South Africa is extremely limited. In a single study of PBIS in South Africa, teachers reported decreased exclusion of learners from class, shouting at learners and beating learners, and increased practices that support learner inclusion (Moodley 2016).

Given the potential of PBIS in the SA context as noted by Dwarika (2020) and Moodley (2016), it would be helpful to understand the extent to which policies and practices in SA schools currently align with PBIS. This is an important first step to a proactive approach wherein support for school personnel can build on these existing policies and practices in the eventual training and implementation of PBIS.

Therefore, the purpose of the present descriptive survey study is to identify the existence of policies and practices that align with the core features of PBIS in a disadvantaged primary school in South Africa. The study focuses on three research questions:

1. What behaviour problems do school staff (i.e. teachers, administrators and non-instructional staff) identify as problematic at their school?

2. To what extent does the target school implement five of the seven core features of PBIS (i.e. a continuum of evidence-based interventions, leadership team implementation and coordination, content expertise and fluency, process integrity and continuous progress monitoring)?

3. Does the target school have a plan for crisis prevention and intervention and if so, what are the components, what is the teachers' role and what is the approach to staff training?

\section{Methods}

\section{Setting and respondents}

The target primary school is in a large urban area in South Africa. The school serves a disadvantaged community of $92 \%$ Coloured residents, where $60 \%$ of the local population lives in poverty (De Lannoy et al. 2018). The neighbourhood surrounding the school has some of the highest rates of murder, gang violence and cases of illegal firearms in the metropolitan area (Department of Community Safety 2019). The school employs 27 teachers and serves approximately 950 learners from kindergarten to Grade 7. In keeping with the PBIS approach that all staff (i.e. teachers, administrators and non-educational staff) are important players in addressing youth behaviour (TAC on PBIS 2015), all staff at the school were invited to participate in the survey.

In terms of known issues with student behaviour and behavioural interventions at the school, it should be noted 
that there are no requirements for the school to have a disciplinary system and whilst it is expected that the ATCP is followed, the school and teachers are not held accountable for adhering to the policy. Also, no formal behavioural data are collected at the school, making it difficult to make assertions of the degree to which serious behavioural issues occurred. However, anecdotal comments from the principal indicated that learner behaviour was a significant concern of teachers. The principal also mentioned issues with learner drug-related behaviours, concerns with youth bringing weapons onto the school grounds and bullying.

\section{Survey development and administration}

A decision was made to develop a survey based on attributes of PBIS, rather than using an existing tool. Other tools (e.g. School-wide Evaluation Tool; Sugai et al. 2005) require an indepth approach to data collection that centres on the collection and analysis of learner data over an extended period of time. As no behaviour data were collected at the school and initiating such a programme was beyond the project resources, it was decided to create a survey that focused more broadly on staff views and implementation of policies and practices that are aligned with PBIS.

The survey was developed following a literature review and was based on five of the seven core features of PBIS (TAC on PBIS 2015) and key aspects of crisis preparedness and intervention. We did not address two features of PBIS: universal and comprehensive screening, and cultural and contextual relevance. Given our understanding that universal and comprehensive screening does not exist in South Africa, we did not address that component.

Gagnon, Barber \& Soyturk (2020) have expressed concerns with the lack of clarity surrounding approaches to making PBIS culturally and contextually relevant, so this component was also omitted. However, crisis preparedness and intervention are addressed, given the concerns with violence in SA schools and issues with gang activity in disadvantaged communities and schools (Department of Community Safety 2019). A focus on preparations to ensure learners' safety is also a building block of the South African National School Safety Framework (Makota \& Leoschut 2016).

Because of space limitations on the survey, the questions focused on schoolwide/universal behavioural supports and interventions, and specific behavioural interventions that teachers reported using in their classes. We did not query participants on specific secondary or tertiary interventions, but included one question concerning how learners in need of intensive, individualised behaviour interventions are identified.

Like in other survey research on PBIS (see Gagnon et al. 2020) and consistent with Campanelli (2008), experts in the field of education and on education in South Africa provided feedback on survey drafts. Comments were solicited concerning (1) formatting, (2) the clarity and appropriateness of the survey questions for the SA context and (3) the alignment of survey questions with the research questions and core features of PBIS. Following this feedback, the survey was revised.

The survey was available in English and in Afrikaans. It was administered in one session after a school day. All participants consented to participate.

\section{Data analysis}

Quantitative data analysis of closed-ended survey questions included descriptive statistics (i.e. frequency and per cent). When reporting percentages for forced-choice questions (i.e. 'check one response' questions), we made calculations using the number of participants who answered the specific questions. Where participants were asked to check 'all that apply', we reported the frequency and the percentage based on the number of respondents that made a specific choice, divided by the total sample of 28 participants. The content analysis of the open-ended survey questions followed the inductive approach recommended by Lincoln and Guba (1985) and taken by previous researchers (Gagnon, Barber \& Soyturk 2018), where responses for each question are coded independently as units of analysis and categorised by the first author and a co-author. We then compared our information and refined the categories. The responses were again independently coded. We conducted a final discussion to come to an agreement on any discrepancies with the coded responses and counted the final number of coded responses within each category for each question. The final reliability for the open-ended responses was 100\%.

\section{Ethical considerations}

The University of Florida Institutional Review Board reviewed and approved the research (2013-U-0753).

\section{Results \\ Respondents}

There were a total of 28 survey respondents; however, not every person answered every question completely. The majority were teachers $(64 \% ; n=18)$. Three respondents indicated that they were part of management and three other respondents reported that they were non-educational staff. Two respondents indicated the 'Other' category, one in charge of school safety and the other a substitute teacher. Two respondents did not note their position.

\section{Common problem behaviours within the school}

To address Research Question 1 (What behaviour problems do school staff identify as problematic at their school?), respondents were asked to mark all applicable learner behaviours that were problematic at the school. Twenty-four respondents $(85.7 \%)$ indicated that disruption was a problem behaviour. Twenty-three respondents $(82.1 \%)$ indicated that the use of inappropriate language and not doing or not completing homework were problems. Twenty-two 
respondents $(78.6 \%)$ responded that three behaviours (verbal harassment of others, lying and incomplete classwork) were of concern. Also reported by many respondents as concerns were defiance $(71.4 \% ; n=20)$, physical aggression $(67.9 \% ; n=$ $19)$ and damaging property $(57.1 \% ; n=16)$. Less frequent were: truancy $(42.9 \% ; n=12)$, sleeping in class $(39.2 \% ; n=11)$, tardiness $(35.7 \% ; n=10)$, theft $(28.6 \% ; n=8)$, possession of drugs/alcohol/tobacco $(28.6 \% ; n=8)$ and possession or use of a weapon $(14.2 \% ; n=4)$. The following as concerns were each identified by one participant: bullying, youth with learning barriers not being able to do the work and causing discipline problems, poor social collaboration and poor moral values and degradation thereof.

\section{Implementation of the five core features of positive behavioural interventions and supports}

To address Research Question 2 (To what extent does the target school implement five core features of PBIS?), respondents were asked a series of questions related to each core feature.

\section{Continuum of evidence-based interventions}

Respondents identified all interventions available for all learners. Fourteen $(50 \%)$ of the respondents reported the availability of punishments/sanctions, and nine (32.1\%) of removing the learner from the class. For more positive approaches, six (21.4\%) identified the availability of rewards / reinforcement and two $(7.1 \%)$ indicated that cognitive or skills training programmes were available. One respondent reported that none of the above interventions were available to all learners and another respondent (non-educational staff) reported not knowing which interventions were available. In terms of how rules and consequences are taught, respondents selected all options that applied. Most respondents reported that the rules and consequences were taught in the classroom (67.9\%; $n=19$; see Table 1). Most commonly, rules and consequences were taught daily $(52 \%, n=13)$. In terms of assessing learner understanding and where rules and consequences are posted, respondents chose all that apply. Most commonly, rules and consequences were not assessed $(42.9 \% ; n=12)$ and were typically posted in classrooms $(64.3 \% ; n=18)$.

Respondents were asked to write which specific strategies they use most often to prevent learner problem behaviours. The most common responses were to use negative consequences: stay after school or in class during break time (35.7\%; $n=10)$. Other responses included: keep learners engaged $(64.3 \% ; n=8)$, use praise or reinforcement $(25 \% ; n=7)$ and use negative consequences: reprimand or remove activities/items $(17.9 \% ; n=5)$. Four respondents $(14.3 \%)$ noted each of the following: time-out or separation from peers, contact parents and contact other professionals or use of disciplinary committee. Less frequent responses included use negative consequences to make learners complete an undesired activity $(10.7 \% ; n=3), \mathrm{CP}(7.1 \% ; n=2)$ and contacting the principal $(3.6 \% ; n=1)$. Three responses were unclear.
TABLE 1: Continuum of evidence-based interventions.

\begin{tabular}{|c|c|c|}
\hline Survey Items & Number & $\%$ \\
\hline \multicolumn{3}{|c|}{ How do teachers provide rules and consequences that apply to all learners? } \\
\hline Verbally & 16 & - \\
\hline In writing & 11 & - \\
\hline Taught in the classroom & 19 & - \\
\hline Not explicitly provided & 1 & - \\
\hline \multicolumn{3}{|c|}{$\begin{array}{l}\text { How often do teachers teach the rules and consequences that apply to all } \\
\text { learners? }\end{array}$} \\
\hline Learners are not taught behaviour expectations and consequences & 1 & 4 \\
\hline Daily & 13 & 52 \\
\hline Weekly & 0 & 0 \\
\hline Monthly & 0 & 0 \\
\hline During orientation for new learners & 2 & 8 \\
\hline No set schedule & 9 & 36 \\
\hline \multicolumn{3}{|c|}{$\begin{array}{l}\text { How do teachers assess understanding of the rules and consequences that apply } \\
\text { to all learners? }\end{array}$} \\
\hline Not assessed & 12 & - \\
\hline Via paper and pencil tests or quizzes & 4 & - \\
\hline Informally by staff & 9 & - \\
\hline Via formal (oral) recitation & 5 & - \\
\hline \multicolumn{3}{|c|}{ Rules and consequences are readily available in which of the following locations? } \\
\hline Message book/school diary & 6 & - \\
\hline Rules are not posted & 5 & - \\
\hline Classrooms & 18 & - \\
\hline Administrative offices & 6 & - \\
\hline Media centres (e.g., library, computer lab) & 5 & - \\
\hline Common areas (e.g., hallways, lunchroom, foyer) & 4 & - \\
\hline
\end{tabular}

Note: Only frequencies for items in a Check All That Apply response are reported.

Respondents were also asked to write which specific strategies they use most in response to learner problem behaviours. The most common response was to contact or send the learner to the principal $(25 \% ; n=7)$, followed by contacting the parents $(14.3 \% ; n=4)$. Three respondents $(10.7 \%)$ noted each of the following: talk to the learner, stay after school or in class during break time, reprimand or remove activities/items and time-out or separation from peers. Contacting other professionals, using the disciplinary committee and reinforcing other learners were selected by one respondent each (3.5\%). Three responses were unclear.

In terms of behavioural expectations and consequences, $92.6 \%$ $(n=26)$ reported that the school has a written policy that focuses on learned behaviour, whilst the remaining two respondents, both teachers, responded that it does not. Only 18 respondents responded to a question asking how the behaviour policy is stated, with $44.4 \%(n=8)$ identifying that the written policy was written both positively and negatively (i.e. what learners should do and what learners should not do). Also, 22.2\% $(n=4)$ responded that it was written positively, and $5.6 \%(n=1)$ reported that it was written negatively. Finally, $16.7 \%$ of respondents $(n=3$; one non-educational staff member, two teachers) did not know how the policy was written.

\section{Content expertise and fluency}

One survey question focused on promoting content expertise and fluency regarding learner behaviour. Respondents were asked to check all responses that applied to their school. Most frequently, they responded that the school management team/ 
School Governing Body Board selects programmes based on research for implementation at the school $(25 \% ; n=7)$ and that staff attend professional development opportunities (17.8\%; $n$ $=5)$. Less frequently, teachers develop a plan for continuous improvement and training $(14.2 \% ; n=4)$, school administrators seek consultation to build and sustain effective behaviour practices $(10.7 \% ; n=3)$ and teachers join groups or networks focusing on learner behaviour $(10.7 \% ; n=3)$.

\section{Leadership team implementation and coordination}

Twenty-five $(89.3 \%)$ respondents noted that there was a team or committee responsible for learner behaviour at the school. Of the three respondents who reported there was no committee, one was a teacher, one was a non-educational staff member and one did not identify their role. The most common professionals in the committee were teachers (57.1\%; $n=16$; see Table 2) and School Governing Body Board members $(32.1 \% ; n=9)$. Almost no other school staff member was reportedly in the committee. Also, four respondents responded that the committee was not functional. Most respondents noted that the committee meets and reports to staff less than once a month $(81.8 \%$, $n=18 ; 84.2 \%, n=16$, respectively). Respondents selected all applicable options concerning the process of developing rules and consequences that apply to all learners. Most commonly, these were developed by the School Governing Body $(64.2 \% ; n=18)$ and the principal $(39.2 \% ; n=11)$.

\section{Process integrity}

Concerning process integrity, the respondents were asked to rate the extent to which teachers follow the school policy for

TABLE 2: Leadership team implementation and coordination.

\begin{tabular}{lcc}
\hline Survey Items & Number & $\%$ \\
\hline The learner behaviour committee includes & 16 & - \\
Teachers & 2 & - \\
Non-teaching staff & 3 & - \\
Security staff & 1 & - \\
Counsellors or psychologists & 0 & - \\
Community members & 0 & - \\
Learners & 2 & - \\
Parents or legal guardians & 9 & - \\
School Governing Body Board members & 18 & 81.82 \\
Which best describes how often the learner behaviour committee meets? & 3 & 13.64 \\
Less than once a month & 1 & 4.54 \\
Once a month & 16 & 84.2 \\
More than once a month & 2 & 10.5 \\
Which best describes how often the learner behaviour committee reports to staff? \\
Less than once a month & 1 & 5.3 \\
Once a month & 11 & - \\
More than once a month & 7 & - \\
Which best describes your school's adoption process for school rules? & 1 & - \\
No specific process & 9 & - \\
Department of Education decision & 11 & - \\
Principal decision & 18 & - \\
School management team decision & & - \\
School Governing Body decision & & - \\
\hline
\end{tabular}

Note: Only frequencies for items in a Check All That Apply response are reported. learner behaviour. The most common responses were that the teachers either followed the policy 'most of the time' $(25 \% ; n=7)$ or 'sometimes' $(25 \% ; n=7)$. Five respondents $(17.8 \%)$ reported that the teachers followed the policy 'rarely'. Only two respondents $(7 \%)$ indicated that the teachers 'always' follow the school policy. Two respondents (17.9\%) also indicated that teachers 'never' follow the behavioural policies. The respondents were also asked to identify all applicable evaluation approaches to ensure that teachers are following the behavioural policy. Thirteen respondents $(46.4 \%)$ stated that no approaches are used to evaluate whether teachers are following the policy for learner behaviour. Five individuals (17.9\%) responded that teachers are directly observed, whereas three individuals (10.7\%) responded that each teacher is questioned regarding the behavioural policies and procedures. One respondent stated that the teacher's disciplinary data are reviewed and another stated that the teacher's use of rewards and reinforcements is reviewed to evaluate whether the teachers implement the behavioural policies and procedures correctly.

\section{Continuous progress monitoring}

Several survey questions addressed approaches to continuous progress monitoring. Respondents were asked to check all answers that apply concerning which professionals address minor and major problem behaviours. For minor problems, respondents indicated that teachers were primarily responsible (92.8\%; $n=26$; see Table 3). All respondents indicated that major problem behaviours were mostly addressed by the principal $(100 \% ; n=28)$. In addition to the other choices marked, two respondents wrote that the School Governing Body Board was responsible for addressing major problem behaviours. When asked how often teachers refer learner behaviour problems to the learner behaviour committee, most respondents reported 'far too little' $(61.9 \%, n=13)$, to the principal 'far too much' $(44 \%, n=11)$, and to the learner management team 'far too little' $(42.9 \%, n=6)$. Three teachers reported that there was no learner management team.

Concerning collecting and using data and in terms of the school discipline referral form, 10 respondents (35.7\%) reported that there was no form. Amongst those who identified the presence of a form, participant understanding varied. The following number of respondents indicated the form included: learner grade $(35.7 \% ; n=10)$, date $(35.7 \%$; $n=10)$, time $(35.7 \% ; n=10)$, the staff member who reported the problem behaviour $(14.2 \% ; n=4)$, problem behaviour $(28.5 \% ; n=8)$, location of behavioural violation $(25 \% ; n=7)$, persons involved (including staff) $(25 \% ; n=7)$, probable motivation for the violation $(21.4 \% ; n=6)$, administrative decision $(21.4 \% ; n=6)$ and recommendations for remediation $(10.7 \% ; n=3)$. Respondents were also asked to note all the ways that discipline data are used for making decisions concerning the learner behaviour policy at their school. Half of the respondents responded that the data are not used $(n=14)$. When queried on the ways in which the school identifies learners who need intensive, individualised behaviour interventions, responses were varied, but 
TABLE 3: Continuous progress monitoring.

\begin{tabular}{|c|c|c|}
\hline Survey Items & Number & $\%$ \\
\hline \multicolumn{3}{|l|}{ Who typically addresses minor behaviour problems? } \\
\hline Classroom teacher & 26 & - \\
\hline Head of department & 6 & - \\
\hline Principal & 12 & - \\
\hline Deputy principal & 7 & - \\
\hline Who typically addresses major behaviour problems? & & - \\
\hline Classroom teacher & 5 & - \\
\hline Head of department & 8 & - \\
\hline Principal & 28 & - \\
\hline Deputy principal & 8 & - \\
\hline \multicolumn{3}{|l|}{$\begin{array}{l}\text { Which best describes how often teachers refer learner } \\
\text { behaviour problems to the learner behaviour committee? }\end{array}$} \\
\hline Far too little & 13 & 61.9 \\
\hline Too little & 4 & 19 \\
\hline About right & 2 & 9.5 \\
\hline Too much & 1 & 4.8 \\
\hline Far too much & 1 & 4.8 \\
\hline \multicolumn{3}{|l|}{$\begin{array}{l}\text { Which best describes how often teachers refer learner } \\
\text { behaviour problems to the principal? }\end{array}$} \\
\hline Far too little & 0 & 0 \\
\hline Too little & 3 & 12.0 \\
\hline About right & 6 & 24.0 \\
\hline Too much & 5 & 20.0 \\
\hline Far too much & 11 & 44.0 \\
\hline \multicolumn{3}{|l|}{$\begin{array}{l}\text { Which best describes how often teachers refer learner } \\
\text { behaviour problems to the learner management team? }\end{array}$} \\
\hline Far too little & 6 & 42.9 \\
\hline Too little & 3 & 21.4 \\
\hline About right & 2 & 14.3 \\
\hline Too much & 2 & 14.3 \\
\hline Far too much & 1 & 7.1 \\
\hline \multicolumn{3}{|l|}{$\begin{array}{l}\text { In what ways are discipline data used for making decisions } \\
\text { concerning the learner behaviour policy at your school? }\end{array}$} \\
\hline None & 14 & - \\
\hline Used to design the learner behaviour policy & 1 & - \\
\hline Used to improve teacher implementation & 1 & - \\
\hline Used to revise the learner behaviour policy & 2 & - \\
\hline \multicolumn{3}{|l|}{$\begin{array}{l}\text { How does the school identify learners who need intensive, } \\
\text { individualised behaviour interventions? }\end{array}$} \\
\hline Frequency of discipline referrals & 6 & - \\
\hline Occurrences of aggressive or violent behaviour & 6 & - \\
\hline Staff-reported assessments of learner behaviour & 5 & - \\
\hline Psychological assessments or screenings & 0 & - \\
\hline Observation of learner behaviour & 12 & - \\
\hline Learner and/or staff interview & 1 & - \\
\hline Review of learner record from prior school placement(s) & 5 & - \\
\hline
\end{tabular}

Note: Only frequencies for items in a Check All That Apply response are reported.

respondents most commonly identified that it was done via observation of learner behaviour $(42.8 \%$; $n=12$; see Table 3).

\section{Crisis preparedness and intervention}

To address Research Question 3 (Does the target school have a plan for a crisis prevention and intervention and if so, what are the components, what is the teachers' role and what is the approach to staff training?), respondents were queried on a plan for crisis prevention and intervention, the teachers' role and the approach to staff training. Only $46.2 \%(n=12)$ asserted that there was a school crisis policy for responding to extreme, dangerous situations relating to learner behaviour and $53.8 \%(n=14)$ responded that there was no plan.
Respondents selected all applicable options regarding the crisis policy, consisting of school and classroom preparations $(42.8 \% ; n=12)$ and procedures for how to respond to dangerous situations $(42.8 ; n=12)$. Only one respondent noted the existence of prevention strategies (e.g. conflict resolution programmes) and a plan for discussing the crisis with staff and learners after an incident. In terms of the teachers' responsibility in a crisis, the most common response was calling a school management team member or the principal $(66.7 \%, n=6)$, followed by intervening directly $(22.2 \%, n=2)$ and calling security personnel or police $(11.1 \%$, $n=6)$. No respondents reported that a teacher should call the local Education Department. Respondents were asked to check all options that apply concerning the steps taken to ensure awareness of the crisis intervention policy. Only four respondents answered the question and the following options were each selected by one respondent: (1) train teachers in crisis management, (2) train security staff in crisis management, (3) provide routine follow-up training sessions to review the crisis policy throughout the school year and (4) practise scenarios throughout the year to ensure maintenance of knowledge. No respondents reported that non-teaching staff were trained in crisis management.

\section{Discussion}

The ATCP (South African Department of Education 2000) was a major development in stepping away from the use of CP in SA schools. The central tenets of the ATCP align with multi-tiered systems of behavioural support, such as PBIS. The current study provides the first snapshot of the implementation of policies and practices that align with PBIS and address crisis preparedness and intervention in a disadvantaged SA school. The data offer important implications for research and practice. However, a great deal of work is needed to fully comprehend the extent to which these policies and practices are implemented nationwide and the feasibility of PBIS in this context.

Beyond the implications garnered from responses to individual survey questions, perhaps the most important conclusion about this disadvantaged primary school is that a variety of answers to each question indicate a great deal of confusion and/or misinformation concerning behavioural policies. The lack of consensus, coupled with a continued reliance on reactive and punitive approaches to learner misbehaviour, indicates a lack of training and/or major philosophical differences between respondents and PBIS.

Three primary categories of the learner behaviours of greatest concern emerged: (1) behaviour that disrupts learning or the refusal to complete academic tasks (i.e. classwork and homework), (2) inappropriate verbalisations (e.g. inappropriate language, verbal harassment and lying) and (3) problems with aggressive behaviour (e.g. defiance, physical aggression and damaging property). These results are generally consistent with previous research on learner behaviour in South Africa (Marais \& Meier 2010) and the concerns could be addressed with evidence-based 
interventions that prevent or address problem behaviours, including interventions associated with PBIS.

When queried on the types of intervention that were used to prevent problem behaviours, the most prevalent approaches reported by respondents focused on threats or the implementation of negative consequences, including staying after school or in class during break time. Only seven respondents utilised praise or reinforcement as an approach to preventing misbehaviour. When misbehaviour did occur, there was little consensus on how to respond. Responses were most commonly to impose negative consequences, and the most frequent response, noted by seven members of staff, was to send the learner to the principal and contact the parents. Clearly, there is a disconnect between evidencebased interventions and respondent approaches to prevent and address misbehaviour. Additional research is needed to understand whether approaches are based on a lack of staff understanding of basic principles in behaviour management (e.g. Topkins, Roman \& Mwaba 2015) or on their beliefs in the effectiveness of negative consequences.

Having a schoolwide behaviour plan is a key component of PBIS. Although almost all respondents reported that such a plan did exist, there was considerable disagreement on the extent to which it was stated positively. This indicates that there may be little or no reference to implementation of the schoolwide plan. The lack of adherence to the plan is further substantiated by only seven respondents reporting that the plan was followed 'most of the time'. Follow-up interviews would provide much needed clarity concerning staff views on the schoolwide behaviour plan, and observation studies could verify the true degree of implementation.

In terms of universal behavioural approaches available to all youth, respondents most frequently noted that rules and consequences were taught by teachers in the classrooms daily. However, 12 respondents noted that learner understanding is not assessed. Respondents were asked to report the universal interventions available to all youth and the interventions that they all use to prevent and respond to misbehaviour. From the available universal interventions, half of the respondents reported punishments/sanctions and another third reported removal of the learner from the class. Only six respondents noted the availability of rewards/reinforcement, again indicating the overwhelming focus on reactive, punitive and exclusionary approaches to learner misbehaviour. This pattern was maintained in the written responses of respondents concerning the most frequent approaches to preventing and addressing learner misbehaviour. However, to prevent misbehaviour, eight respondents also noted that they implemented approaches to maintain learner engagement. There are relatively few respondents, considering that promoting academic engagement positively affects learner behaviour (Harbour et al. 2015). Another trend is that whilst the approaches to dealing with learner misbehaviour were quite varied, the most common response was to involve the principal. The infrequent use of positive consequences and the indication that respondents did not feel competent in dealing with misbehaviour further indicate the need for training.

The effects of insufficient training are compounded by the lack of oversight in ensuring the implementation of the schoolwide behaviour plan. Almost half of the respondents noted that there was no policy for ensuring appropriate implementation. Even if any appropriate plan did exist or was developed, without fidelity of implementation, there is little likelihood that the plan would be effective. The lack of oversight should be considered alongside the fact that only five respondents noted that opportunities existed for professional development. Research is sorely needed on effective approaches to developing and implementing plans for professional development and oversight to ensure the appropriate implementation of the schoolwide behaviour plan, particularly in the SA context.

A leadership team is one component of PBIS that provides a mechanism to monitor and guide the implementation of behavioural supports. Almost all respondents reported that a team exists. However, in contrast to the PBIS approach, which recommends wide representation comprising adults from across the school, the leadership team at this school almost exclusively comprised teachers and School Governing Body board members. This approach neglects important staff, administrators and parent input.

Regarding continuous progress monitoring, it is unsurprising that teachers overwhelmingly respond to minor difficulties and principals address major behaviour problems. However, given the aforementioned lack of adherence to the schoolwide behaviour plan and the lack of implementation of proactive and positive evidence-based behavioural interventions, teacher autonomy is somewhat concerning. The use of a referral form to record details of behaviour-related incidences was noticeably absent. Only one third of participants identified the existence of a form and, when noting its existence, data on the probable motivations of the learner were almost never collected, making it difficult or impossible to identify and address the function of the learner's behaviour. Moreover, there is decided lack of use of learner's behavioural data to make decisions concerning behavioural policies or to identify whether youths are in need of selective intervention strategies that offer targeted support for those at high risk of behavioural difficulties. Without data, it is also impossible to accurately identify and help learners with more serious undesirable behaviours that need individualised and intensive interventions. Research is needed to more thoroughly understand the impacts of funding, staffing, training and philosophy on the appropriate collection and use of behavioural data.

Almost half of the respondents reported that there was no crisis plan. Those who identified the existence of a plan reported that the plan almost never included prevention 
strategies or a process for discussing a situation with learners and staff after its occurrence. Certainly, the prevalence of violence in SA schools and disadvantaged communities necessitates preparation for such an incident and discussions to mitigate the associated trauma.

\section{Limitations}

The present study is the first descriptive survey of a disadvantaged SA primary school that focuses on current policies and practices within the context of key PBIS components. Nonetheless, the depth of information that can be garnered from a survey is somewhat limited. Future research is needed that triangulates data from interviews, direct observations, reviews of policy documents and behavioural data and surveys. Moreover, it is the present data that cannot be generalised across other SA schools. However, the foundational information provides a starting point for future research on PBIS in South Africa and provides some important practical implications.

\section{Conclusion}

As yet, the potential for PBIS is unrealised in South Africa. Although PBIS aligns with the ATCP, the data indicate that the use of $\mathrm{CP}$ has been replaced with other reactive and punitive approaches. Unfortunately, this is consistent with previous research in South Africa (Motseke 2020). Moreover, in this disadvantaged school, there is little evidence that: (1) a cohesive, evidence-based schoolwide behaviour plan exists that includes multi-tiered systems of support; (2) staff have the expertise to implement a positive and proactive behaviour plan or are provided adequate professional development; (3) staff follow the plan and are held accountable for following it and (4) a representative leadership team provides oversight and direction regarding the plan by using learner behaviour data.

Perhaps, the most substantial practical implication of the present data is that staff could benefit from comprehensive and ongoing professional development that focuses on the central tenets of behaviour management, as well as proactive and positive evidence-based behavioural interventions. In addition, the knowledge would provide a common understanding on which to base discussions of a schoolwide behavioural system that is understood, agreed upon and implemented by all staff.

\section{Acknowledgements Competing interests}

Alignment of school discipline with positive behavioural interventions and supports: The case of one disadvantaged urban South African Primary School.

\section{Authors' contributions}

J.C.G., conceptualised and conducted the research, completed the data analysis and wrote the manuscript. F.J.S., provided translations and recommendations for survey questions. K.M., conducted background research and completed data entry.

\section{Funding information}

This work was supported by a Fulbright Scholarship awarded to the first author.

\section{Data availability}

The data that support the findings of this study are available on request from the corresponding author, [J.C.G.]. The data are not publicly available because of the fact that the containing information could compromise the privacy of research participants.

\section{Disclaimer}

The views and opinions expressed in this article are those of the authors and do not necessarily reflect the official policy or position of any affiliated agency of the authors, and the publisher/s.

\section{References}

Campanelli, P., 2008, 'Testing survey questions', in D. De Leeuw, J.J. Hox \& D.D. Dillman (eds.), International handbook of survey methodology, pp. 176-200, Lawrence Erlbaum Associates, New York, NY.

Centre for Justice and Crime Prevention \& the Department of Basic Education. 2012, 'Addressing bullying in schools', in School safety framework: Course reader, Centre for Justice and Crime Prevention, Cape Town, viewed 9 August 2021, from http://www. cjcp.org.za/uploads/2/7/8/4/27845461/addressing_bullying_in_schools_reader.pdf.

De Lannoy, A., Fortuin, A., Mpofu-Mketwa, T., Mudiriza, G., Ngcowa, S., Storme, E. et al., 2018, Unpacking the lived realities of Western Cape youth. Exploring the well-being of young people residing in five of the most deprived areas in the Western Cape Province, Department of the Premier: Western Cape Government, and Southern Africa Labour and Development Research Unit, University of Cape Town, Cape Town, South Africa, viewed from https://www.westerncape.gov.za/ sites/www.westerncape.gov.za/files/youth_well_being_wc_lowres.pdf.

Department of Community Safety, 2019, Western Cape provincial crime analysis Analysis of Western Cape reported crime based on 2018/2019 crime statistic issued by the South African Police Service on 13 September 2019, Department of Community Safety, Cape Town, South Africa, viewed 9 August 2021, from https:// www.westerncape.gov.za/sites/www.westerncape.gov.za/files/wccs_crime_ report_2020-03-25_medres.pdf.

Dwarika, V.M., 2020, 'Positive behaviour supports in South Africa: Training teachers to implement a systemic strategy', Intervention in School and Clinic 55(3), 192-196. https://doi.org/10.1177/1053451219842212

Gagnon, J.C., Barber, B.R. \& Soyturk, I., 2018, 'Positive behavior interventions and supports implementation in secure care juvenile justice schools: Results of a national survey of school administrators', Behavioral Disorders 44(1), 3-19. https://doi.org/10.1177/0198742918763946

Gagnon, J.C., Barber, B.R. \& Soyturk, I., 2020, 'Policies and practices supporting positive behavioral interventions and supports (PBIS) implementation in Florida Title 1 middle schools', Exceptionality 28(3), 176-194. https://doi.org/10.1080/09 362835.2020 .1727333

Gershoff, E.T. \& Font, S.A., 2016, 'Corporal punishment in U.S. schools: Prevalence, disparities in use, and status in state and federal policy', Social Policy Report 30(1), 1-26. https://doi.org/10.1002/j.2379-3988.2016.tb00086.x

Hanaya, A., McDonald, Z. \& Balie, L., 2020, 'Teacher agency in South African education policy related to school safety', Africa Education Review 17(1), 1-17. https://doi. org/10.1080/18146627.2018.1467734

Harbour, K.E., Evanovich, L.L., Sweigart, C.A. \& Hughes, L., 2015, 'A brief review of effective teaching practices that maximize student engagement', Preventing School Failure: Alternative Education for Children and Youth 59(1), 5-13. https:// doi.org/10.1080/1045988X.2014.919136

Horner, R.H. \& Macaya, M.M., 2018, 'A framework for building safe and effective school environments: Positive behavioural interventions and supports (PBIS)' Pedagogická orientace 28(4), 663-685. https://doi.org/10.5817/PedOr2018-4-663

Lee, A. \& Gage, N.A., 2019, 'Updating and expanding systematic reviews and metaanalyses on the effects of school-wide positive behaviour interventions and supports', Psychology in the Schools 57(5), 783-804. https://doi.org/10.1002/ pits.22336

Lincoln, Y. \& Guba, E., 1985, Naturalistic inquiry, Sage, Thousand Oaks, CA. 
Makota, G. \& Leoschut, L., 2016, 'The national school safety framework: A framework for preventing violence in South African Schools', African Safety Promotion 14(2) 18-23. https://doi.org/10.4314/asp.v14i2

Marais, P. \& Meier, C., 2010, 'Disruptive behaviour in the foundations phase of schooling', South African Journal of Education 30(1), 41-57. https://doi. org/10.4314/saje.v30i1.52601

Mthanti, B. \& Mncube, V., 2014, 'The social and economic impact of corporal punishment in South African schools', Journal of Sociology and Social Anthropology 5(1), 71-80. https://doi.org/10.1080/09766634.2014.11885611

Moodley, V., 2016, 'An investigation into the positive behaviour support model for Limpopo primary schools', Ph.D. thesis, University of the Witwatersrand.

Motseke, M., 2020, 'Managing ill-discipline among learners in disadvantaged schools', Africa Education Review 17(3), 22-36. https://doi.org/10.1080/18146627.2019.1 588747

Moyo, G., Khewu, N.P.D. \& Bayaga, A., 2014, 'Disciplinary practices in schools and principles of alternatives to corporal punishment strategies', South Africa Journal of Education 34(1), 1-14. https://doi.org/10.15700/201412120952

Ncontsa, V.N. \& Shumba, A., 2013, 'The nature, causes and effects of school violence in South African high schools', South African Journal of Education 33(3), 1-15. https://doi.org/10.15700/201503070802

Noltemeyer, A., Palmer, K., James, A.G. \& Wiechman, S., 2019, 'School-wide positive behavioural interventions and supports (SWPBIS): A synthesis of existing research', International Journal of School and Educational Psychology 7(4), 253-262. https:// doi.org/10.1080/21683603.2018.1425169

South African Department of Education, 2000, Alternatives to corporal punishment: The learning experience, South African Department of Education, Pretoria, South Africa, viewed from https://www.westerncape.gov.za/Text/2003/alternatives corporal_punishment.pdf.
South African Human Rights Commission \& UNICEF, 2016, Global goals for every child: Progress and disparities among children in South Africa, UNICEF South Africa, Pretoria,
South Africa, viewed 9 August 2021, from https://www.sahrc.org.za/home/21/files/ South Africa, viewed 9 August 2021, from https://www.sahrc.org.za/home
Global\%20Goals $\% 20$ For $\% 20$ Every $\% 20$ Child $\% 202016 \% 20-\% 20$ FINAL.pdf.

Souverein, F.A., Ward, C.L., Visser, I. \& Burton, P., 2016, 'Serious, violent young offenders in South Africa: Are they life-course persistent offenders?', Journal of Interpersonal Violence 31(10), 1859-1882. https://doi.org/10.1177/0886260515570748

Strauss, A.L. \& Corbin, J.M., 1998, Basics of qualitative research: Techniques and procedures for developing grounded theory, Sage, Thousand Oaks, CA.

Sugai, G., Lewis-Palmer, T., Todd, A. \& Horner, R., 2005, School-wide evaluation tool (SET, Version 2.1), Center for Positive Behavioral Supports, University of Oregon, Eugene, OR

Technical Assistance Center on Positive Behavioural Interventions and Supports, 2015 Positive Behavioural Interventions and Supports (PBIS) implementation blueprint: Part 1 - Foundations and supporting information, University of Oregon, Eugene, OR, Part 1 - Foundations and supporting information, University of Oregon, Eugene, OR,
viewed 9 August 2021, from https://assets.website-files.com/5d3725188825e071f viewed 9 August 2021, from https://assets.website-files.com/5d3725188825e071f 2015\%20Final.pdf.

Topkins, B., Roman, N.V. \& Mwaba, K., 2015, 'Attention deficit disorder (ADHD): Primary school teachers' knowledge of symptoms, treatment and managin classroom behaviour', South African Journal of Education, 35(2), 1-8. https://doi. org/10.15700/saje.v35n2a988

Winaar, L., Arends, F. \& Beku, U., 2018, 'Reducing bullying in schools by focusing on school climate and school socio-economic status', South African Journal of Education 38 (Supplement 1), S1-S10. https://doi.org/10.15700/saje.v38ns1a1596

Women, Children and People with Disabilities, Republic of South Africa, 2014, South Africa's periodic country report on United Nations Convention on the Rights of the Child. Reporting Period: January 1998-April 2013, Women, Children and People with Disabilities, Republic of South Africa, Pretoria, South Africa, viewed 09 August 2021, from https://www.unicef.org/southafrica/media/1431/file/ZAFPeriodic-country-report-on-the-UN-CRC-2014.pdf. 